\title{
PEMBELAJARAN SEJARAH INDONESIA BERBASIS PERISTIWA-PERISTIWA LOKAL DI TASIKMALAYA UNTUK MENINGKATKAN KEMAMPUAN BERPIKIR KRITIS
}

\author{
Yanyan Hardiana \\ Guru IPS SMPN 2 Tasikmalaya \\ hardyans@yahoo.com
}

Abstract:

This paper discusses the importance of local history teaching in schools developed. Learning history or local events are still perceived as a burden by teachers. The causes include a lack of creative teachers in developing the historical material, they focuses on the materials listed in the syllabus of teaching history and minimal or no sources of local history that can be used by teachers as teaching materials in school. This paper focuses on the urgency of learning local history, integrated with the teaching of history in Indonesia. More studies specifically performed on the characters and events that occurred in the area of Tasikmalaya. In this study, the author gives idea in the form of discussions based on periodization in the history of Indonesia. The result showed that in Tasikmalaya there should be plenty of local characters and events that should receive serious attention from all parties to be developed in the teaching of history at school. This is especially important considering the character development should start from the awareness of their identity as part of Indonesian history. Therefore, the development of local history is part of the development of identity as a nation of Indonesia

Abstrak: $\quad$ Artikel ini membahas pentingnya pengajaran sejarah lokal di sekolah-sekolah yang dikembangkan. Belajar sejarah atau kejadian lokal masih dirasakan sebagai beban oleh para guru. Penyebabnya adalah kurangnya guru kreatif dalam mengembangkan materi sejarah, mereka berfokus pada materi yang tercantum dalam silabus sejarah pengajaran dan minimal atau tidak ada sumber sejarah lokal yang dapat digunakan oleh guru sebagai bahan ajar di sekolah. Makalah ini berfokus pada urgensi belajar sejarah lokal, yang terintegrasi dengan pengajaran sejarah di Indonesia. Lebih banyak penelitian dilakukan secara khusus terhadap karakter dan peristiwa yang terjadi di wilayah Tasikmalaya. Dalam penelitian ini, penulis menunjukkan bahwa di Tasikmalaya harus ada banyak karakter dan acara lokal yang harus mendapat perhatian serius dari semua pihak untuk dikembangkan dalam pengajaran sejarah di sekolah. Hal ini sangat penting mengingat pengembangan karakter harus dimulai dari kesadaran akan identitas mereka sebagai bagian dari sejarah Indonesia. Oleh karena itu, perkembangan sejarah lokal merupakan bagian dari pengembangan identitas sebagai bangsa Indonesia

Kata Kunci: $\quad$ Nasionalisme, Patriotisme, toleransi, enrichment Learning History of Indonesia, Local Wisdom

\section{PENDAHULUAN}

Masalah urgen yang seringkali terabaikan dalam pembelajaran sejarah Indonesia, yakni minimnya pembahasan materi sejarah lokal atau peristiwa lokal. Guru sejarah seringkali terpaku pada bahan ajar yang tertuang dalam buku paket mata pelajaran. Guru sejarah jarang memberikan materi pengayaan sejarah Indonesia, khususnya berbasis peristiwa lokal, dengan dalih mengejar target kurikulum. Namun, tidak dipungkiri bahwa tidak sedikit guru sejarah yang kesulitan dalam mengembangkan materi peristiwa lokal dalam pembelajaran sejarah Indonesia. Salah satu penyebabnya adalah minimnya referensi tentang peristiwa-peristiwa lokal tersebut. Lantas mengapa peristiwa-peristiwa lokal tersebut perlu diajarkan?

Pembelajaran sejarah yang berlangsung selama ini yang belum mengintegrasikan peristiwa lokal. Salah satu strategi mengajarkan sejarah lokal adalah melalui pembelajaran sejarah di sekolah pentingnya. Dalam kurikulum 2013 dengan pendekatan saintifik memungkinkan strategi teserbut dapat dilaksanakan. Dengan demikian permasalahan yang akan dikaji adalah bagaimana pembelajaram sejarah Indoesia vang mengintegrasikan /berbasis peristiwa -peristiwa lokal di Tasikmalaya?

\section{Urgensi Pembelajaran Sejarah Lokal}

Guna memahami urgensi dari pembelajaran sejarah lokal, perlu difahami terlebih dahulu apa yang dimaksud dengan sejarah lokal. Taufik Abdullah (Mulyana \& Gunawan, 2007:2) mengemukakan bahwa: "Sejarah lokal dapat didefenisikan sejarah dari suatu "tempat", suatu "locality", yang batasannya ditentukan oleh perjanjian yang diajukan penulis sejarah". Selanjutnya Widja (Mulyana \& Gunawan, 2007:2) menjelaskan "Batasan yang dibuat oleh penulis bisa luas baik dalam aspek keruangannya maupun aspek tema kajiannya. Kajian sejarah lokal yaitu studi tentang kehidupan masyarakat atau khususnya komunitas dari suatu lingkungan sekitar (neighborhood) tertentu dalam dinamika perkembangannya dalam berbagai aspek kehidupan manusia".

Corak studi sejarah lokal yang telah dilakukan tentang Indonesia menurut Taufik Abdullah (Supardi, 2006:124) dapat dibedakan menjadi empat golongan, yakni: (1) Studi yang difokuskan pada suatu peristiwa tertentu (studi peristiwa dan Peneliti Sejarah, p-issn:2620-4789| e-issn:2615-7993 
khusus atau apa yang disebut evenemental l'evenement), (2) Studi yang lebih menekankan pada struktur, (3) Studi yang mengambil perkembangan aspek tertentu dalam kurun waktu tertentu (tematis), dan (4) Studi sejarah umum yang menguraikan perkembangan daerah tertentu (provinsi, kota, kabupaten) dari masa ke masa.

Dalam konteks mengembangkan sejarah lokal, diperlukan pendidikan yang mampu menanamkan nilai-nilai multikultural dalam kehidupan peserta didik agar tercipta generasi muda yang mampu menciptakan keharmonisan dalam bermasyarakat. Hasan (2012: 102) mengemukakan pendapat bahwa "Pendidikan adalah suatu usaha sadar manusia mempersiapkan generasi mudanya. Dalam mempersiapkan generasi muda tersebut pendidikan harus mulai dari apa yang sudah dimilikinya dan apa yang sudah diketahuinya. Apa yang sudah dimilikinya dan sudah diketahuinya itu adalah apa yang terdapat pada lingkungan terdekat peserta didik terutama pada lingkungan budayanya. Prinsip ini berkenaan dengan cara bagaimana peserta didik belajar".

Pembelajaran sejarah adalah salah satu upaya yang tepat untuk menyelipkan pendidikan nilai multikultural di dalamnya. Sjamsuddin dan Ismaun (1996: 10) mengemukakan bahwa "Sejarah adalah suatu ilmu pengetahuan tentang rangkaian kejadian yang berkausalitas pada masyarakat manusia dengan segala aspeknya serta proses gerak perkembangannya dari awal sejarah hingga saat kini yang berguna bagi pedoman kehidupan masyarakat masa sekarang serta arah cita-cita masa depan”.

Dalam kaitan dengan hal itu, Winarti (XX:6) menjelaskan bahwa ada beberapa hal pentingnya mempelajari sejarah lokal antara lain: (1) Untuk menilai kembali generalisasi-generalisasi yang sering terdapat dalam sejarah nasional (periodisasi,dualisme ekonomi,dll.), (2) Meningkatkan wawasan/ pengetahuan kesejahteraan dari masing-masing kelompok yang akhirnya akan memperluas pandangan tentang "dunia" Indonesia, (3) Membantu sejarawan profesional membuat analisis-analisis kritis. Dan, (4) Menjadi sumber/ bahan/ data sejarah dalam penelitian.

Hal tersebut dipertegas oleh Supardan (2004:262) yang menyatakan bahwa "Pembelajaran sejarah lokal perlu dikenalkan pada siswa untuk mengenali identitas kelokalannya maupun menghargai identitas etnis/daerah lain yang ada di Indonesia dengan mempertimbangkan azas belajar dan tahap perkembangan siswa. Pemerintah pusat dan daerah, guru-guru sejarah dilapangan harus berusaha sekuat-kuatnya utnuk mendorong terlaksananya pembelajaran sejarah lokal di sekolah-sekolah".

Dengan pembelajaran sejarah yang berbasis sejarah lokal, maka guru akan dengan mudah menamkan nilai-nilai multikulturalisme dalam diri peserta didik. Mahendrawati dan Syafei (Naim \& Achmad Sauqi, 2012:126) mengemukan bahwa "Multikulturalisme sebenarnya merupakan konsep dimana sebuah komunitas dalam konteks kebangsaan dapat mengakui keberagaman, perbedaan, dan kemajemukan budaya, baik ras, suku, etnis dan agama. Sebuah konsep yang beragam (multikultur). Bangsa yang multikultur adalah bangsa yang kelompok-kelompok etnik atau budaya (etnic and cultural groups) yang ada dapat hidup berdampingan secara damai dalam prinsip co-existence yang ditandai oleh kesediaan untuk menghormati budaya lain. Pluralitas ini juga ditangkap oleh agama, selanjutnya agama mengatur untuk menjaga keseimbangan masyarakat yang plural tersebut".

Hasan (2012:6) mengemukakan tujuan pendidikan sejarah sebagai bagian dari pendidikan IPS adalah: (1) Memiliki pengetahuan dan pemahaman tentang berbagai peristiwa sejarah penting dan esensial untuk membangun memori kolektif sebagai bangsa, (2) Mengembangkan semangat kebangsaan, (3) Mengembangkan daya berfikir kritis dan kreatif, (4) Mengembangkan rasa ingin tahu, (5) Preservasi kecemerlangan masa lalu, (6) Mengembangkan kejujuran, kerja keras dan tanggungjawab, (7) Mengembangkan nilai dan sikap kepahlawanan, kepemimpinan dan inspirasi, (8) Mengembangkan persahabatan dan kepedulian social, (9) Mengembangkan kemampuan komunikasi, (10) Mengembangkan kemampuan mencari, mengolah, mengemas dan mengkomunikan informasi.

Hal ini dipertegas oleh Wiriatmadja (2002:156-157) yang mengemukakan bahwa Pengajaran sejarah adalah untuk membangkitkan kesadaran empatik (emphatic awareness) di kalangan peserta didik, yaitu sikap empati dan toleransi terhadap orang lain yang disertai dengan kemampuan mental untuk imajinasi dan kretivitas, jika sejarah dipahami dengan benar oleh peserta didik. Pengajaran sejarah nasional di sekolah, bagaimanapun akan memperkenalkan peserta didik kepada pengalaman kolektif dan masa lalu bangsanya. Pengajaran ini juga membangkitkan kesadaran dalam kaitannya dengan kehidupan bersama dalam komunitas yang lebih besar, sehingga tumbuh kesadaran kolektif dalam memiliki kebersamaan dalam sejarah. Proses pengenalan diri inilah yang merupakan titik awal dari timbulnya rasa harga diri, kebersamaan, dan keterikatan (sense of solidarity), rasa keterpautan dan memiliki (sense of belonging) kemudian rasa bangga (sense of pride) terhadap bangsa dan tanah air.

Dari gambaran di atas, dapat diambil sebuah konklusi bahwa urgensi pembelajaran sejarah local dalam pembelajaran sejarah nasional terlihat dari adanya korelasi yang sangat erat terkait keberadaan peristiwa lokal dalam sejarah nasional Indonesia.

\section{Peristiwa-Peristiwa Lokal di Tasikmalaya}

Tasikmalaya, seperti daerah lainnya, merupakan salah satu bagian dari wilayah Negara Kesatuan Republik Indonesia. Sebagai daerah yang tidak begitu jauh dengan pusat kekuasaan provinsi dan pusat. Tasikmalaya memiliki peristiwaperistiwa lokal yang secara langsung maupun tidak langsung mempengaruhi jalannya roda sejarah bangsa Indonesia. Peristiwa-peristiwa lokal tersebut ada yang bernuansa politik, sosial, ekonomi, maupun budaya. Bahkan ada beberapa peristiwa di Tasikmalaya yang telah menjadi wacana sejarah nasional. Dari sekian banyak peristiwa-peristiwa lokal di Tasikmalaya, diantaranya ialah:

HISTORIA: Jurnal Pendidik dan Peneliti Sejarah, p-issn:2620-4789 | e-issn:2615-7993 


\begin{tabular}{|c|c|c|}
\hline Periodisasi & Materi Pokok Pelajaran & Peristiwa Lokal Tasikmalaya \\
\hline Masa Pra Aksara & $\begin{array}{l}\text { Ciri-ciri Kehidupan Manusia } \\
\text { Purba }\end{array}$ & Peninggalan Purbakala di Karangnunggal, Situs Situ Gede \\
\hline Masa Hindu-Budha & $\begin{array}{l}\text { Kerajaan Bercorak Hindu } \\
\text { Budha }\end{array}$ & Kerajaan Galunggung, Sejarah Kampung Naga, \\
\hline \multirow{4}{*}{ Masa Islam } & Tokoh-Tokoh Masa Hindu & Yudanegara \\
\hline & Kerajaan Bercorak Islam & Kerajaan Sukapura, \\
\hline & Tokoh-Tokoh Masa Islam & Syech Abdul Muhyi, Siti Munigar, \\
\hline & Saluran Penyebaran Islam & Sejarah Pesantren di Tasikmalaya \\
\hline Masa Kolonialisme Barat & $\begin{array}{l}\text { Masa VOC s.d. Masa Ekonomi } \\
\text { Liberal }\end{array}$ & Tasikmalaya era Preanger Stelsel (Perkebunan Salopa) \\
\hline \multirow[t]{3}{*}{$\begin{array}{l}\text { Masa Pergerakan Nasional } \\
\text { Indonesia }\end{array}$} & $\begin{array}{l}\text { Karakteristik Organisasi } \\
\text { Pergerakan Nasional }\end{array}$ & Paguyuban Pasundan \\
\hline & Peristiwa Penting & Pemberontakan Nyi Aciah, Pemberontakan SI Afdeling B \\
\hline & $\begin{array}{l}\text { Tokoh-Tokoh Masa Pergerakan } \\
\text { Nasional }\end{array}$ & Sutisna Sendjaja, Dr. Sukardjo \\
\hline \multirow[t]{2}{*}{ Masa Pendudukan Jepang } & Peristiwa-Peristiwa Penting & Pemberontakan Sukamanah \\
\hline & $\begin{array}{l}\text { Tokoh Masa Pendudukan } \\
\text { Jepang }\end{array}$ & Kyai Haji Zainal Mustafa \\
\hline \multirow[t]{3}{*}{$\begin{array}{l}\text { Masa Perang Kemerdekaan } \\
\text { Indonesia }\end{array}$} & Perjuangan Fisik (Bertempur) & $\begin{array}{l}\text { SejarahTasikmalaya Ibukota Provinsi Pasca Bandung } \\
\text { Lautan Api, Lahirnya Lahirnya Divisi Siliwangi, } \\
\text { Pertempuran Karang Resik, Pertempuran Mangkubumi }\end{array}$ \\
\hline & Perkembangan Ekonomi & Kongres I Koperasi Indonesa di Tasikmalaya \\
\hline & $\begin{array}{l}\text { Tokoh-Tokoh Masa Perang } \\
\text { Kemerdekaan Indonesia } \\
\end{array}$ & $\begin{array}{l}\text { Mayor Utarya, Kapten Naseh, Letnan L.S Tobing, Komir } \\
\text { Kostaman, Letnan Jaelani }\end{array}$ \\
\hline Sejarah Seni dan Budaya & Hasil-Hasil Seni dan Budaya & $\begin{array}{l}\text { Asal-Usul Kerajinan Batik Tasik, Kerajinan K,ertas van } \\
\text { Tasik, Kelom Geulis, Seni Reog Abad Atum, Kerajinan } \\
\text { Rajapolah }\end{array}$ \\
\hline
\end{tabular}

\section{Implementasi Pembelajaran Sejarah Lokal di Sekolah}

Dalam pembelajaran sejarah lokal, terdapat beberapa hal yang harus diperhatikan yaitu pertama penyajian materi, kedua teknik pembelajaran dan ketiga penilaian yang digunakan. Sebagaimana telah dikemukan bahwa pendekatan pembelajaran sejarah lokal jangan hanya sekedar menampilkan sejarah sebagai peristiwa saja. Pembelajaran sejarah lokal pun harus mengikuti kecenderungan perkembangan penulisan sejarah pada umumnya. Perkembangan penulisan sejarah dirincikan dengan menekankan analisis daripada bercerita; menekankan tema-tema atau topik-topik daripada kronologi; mengandalkan statistik, wawancara lisan, model-model sosiologi dan teori psiko-analisis. Fokus baru dalam penulisan sejarah yaitu kelompok-kelompok sosial seperti keluarga, masalah-masalah sosial, pabrik dan perusahaan, kelahiran dan kematian, masa kanak-kanak dan masa tua, kriminalitas dan penyakit kejiwaan. Penulisan sejarah baru tidak lagi menekankan kepada penulisan kelompok elite (Mulyana \& Restu Gunawan, 2007:7).
Pembelajaran sejarah lokal, dapat dimplementasikan di sekolah melalui pembelajaran sejarah nasional. Dalam arti lain, peristiwa-peristiwa lokal dapat disisipkan dalam pembelajaran sejarah nasional, dengan cara mencari kesuaian tema/pokok bahasan dalam Silabus Sejarah Nasional dan dijabarkan dalam bentuk modifikasi Rencana Pelaksanaan Pembelajaran (RPP) yang mengembangkan kreatifitas berfikir siswa. Hal ini dapat dilakukan dengan cara mengembangkan kemampuan berfikir siswa secara kritis. Dalam hal ini, Hasan (2008:5) mengemukakan, bahwa:

"Kemampuan berfikir kritis dalam sejarah adalah kemampuan mencari dan menentukan sumber informasi yang valid, kemampuan mengumpulkan informasi dari berbagai sumber sejarah, kemampuan mengelompokkan informasi tersebut dalam berbagai klasifikasi, kemampuan menentukan hubungan antar informasi dalam klasifikasi dan antarklasifikasi, kemampuan memberi makna terhadap hubungan informasi, kemampuan membangun cerita sejarah. Kemampuan keterkaitan antar informasi haruslah berdasarkan kemampuan dalam menerapkan pemahaman mengenai hubungan sebab akibat dan

HISTORIA: Jurnal Pendidik dan Peneliti Sejarah, p-issn:2620-4789 | e-issn:2615-7993 
Secara spesifik dalam konteks pembelajaran sejarah lokal kemampuan berfikir kritis tersebut disesuaikan jenjang pendidikan peserta didik, seperti yang dijelask oleh Hasan dalam Mulyana (2007:189-190), berikut ini:

"Pada jenjang pendidikan menengah (SMA), tujuan pendidikan sejarah lebih dikembangkan untuk mempersiapkan peserta didik untuk meniti pendidikan pada jenjang pendidikan tinggi. Karena itu, tulisan ini menekankan untuk mengembangkan kemampuan pemahaman maupun skills yang diperlukan dalam sejarah. Kemampuan yang dimaksud seperti historical thinking, historical analysis and interpretation, dan historical research capability dapat dikembangkan sebagi focus utama. Dalam kaitan dengan hal ini, posisi materi sejarah local yaitu peristiwa sejarah lokal tidak lagi sebagai sumber semata tetapi juga menjadi objek studi sejarah peserta didik. Dalam kesempatan inilah mereka belajar mengembangkan wawasan, pemahaman, dan keterampilan sejarah. Mereka dapat berhubungan langsung dengan sumber asli dan mengkaji sumber asli dalam suatu proses penelitian sejarah. Mereka dapat melatih diri dalam penafsiran sejarah dan kalau pun terjadi berbagai perbedaan di antara mereka maka itu akan memiliki nilai pendidikan yang sangat tinggi.

Sementara pendekatan pembelajaran sejarah yang tepat, Supriatna (2005:113-131) mengemukan pendekatan konstruktivisme, seperti dijelaskan berikut ini:

"pendekatan konstruktivisme dalam pembelajaran sejarah yang bermuara pada pengembangan kemampuan guru dalam membangkitkan kemampuan berfikir kritis siswa. Pendekatan konstruktivisme dapat digunakan oleh guru sejarah dalam mengembangkan materi ajar di kelas. Selama ini, pengajaran sejarah di sekolah masih menggunakan pendekatan tradisional seperti ceramah, diskusi, dan lain-lain, serta lebih menekankan pada aspek-aspek kognitif dan mengabaikan keterampilanketerampilan social dalam sejarah. Konsekuensi dari metode tersebut adalah siswa merasa bosan terhadap materi pelajaran sejarah dan dalam jangka panjang, tentu saja, akan menjadi penurunan kualitas pembelajaran sejarah.

Pendekatan konstruktivisme mengharuskan guruguru untuk melakukan hal-hal berikut ini: (1) mendorong dan menerima otonomi dan inisiatof siswa dalam mengembangkan materi pembelajaran, (2) menggunakan data mentah dan sumber utama (primary resources), termasuk sumber-sumber pelaku utama sejarah, untuk dikembangkan dan didiskusikan bersama-sama dengan siswa di kelas, (3) memberikan tugas kepada siswa untuk mengembangkan klasifikasi, analisis, melakukan, prediksi terhadap peristiwa sejarah, dan menciptakan konsep-konsep baru, (4) berdifat fleksibel terhadap response dan interpretasi siswa dalam masalah-masalah sejarah, bersedia mengubah strategi pembelajaran yang tergantung pada minat siswa, serta vmengubah isi pelajaran sesuai dengan situasi dan kondisi siswa. (5) memfasilitasi siswa untuk memahami konsep sambil mengembangkannya melalui dialog dengan siswa, (6) mengembangkan dialog antara guru dengan siswa dan siswa dengan rekan-rekannya, (7) menghindari alat tes untuk mengukur keberhasilan siswa, (8) mendorong siswa untuk membuat analisis dan elaborasi terhadap masalah-masalah controversial yang dihadapinya, (9) mengembangkan aspek kontrasiksi dan kontroversi untuk ditarik dalam KBM di kelas, (10) member peluang kepada siswa untuk berfikir mengenai masalah yang dihadapi siswa, (11) member peluang kepada siswa untuk membangun jaringan konsep serta membentuk metaphora.

Dalam kurikulum 2013, pendekatan saintifik (mengamati, menanya, mengumpulkan informas, mengasosiasi, dan mengomunikasikan) akan menjadi ruh pembelajaran dengan berbagai model pembelajaran. Tiga model yang dikembangkan dalam Kurikulum 2013, seperti PBL (Problem Based Learning), DL (Discovery Learning), dan PjBL (Project Based Learning), akan dapat mengembangkan pembelajaran sejarah local secara optimal. Kondisi tersebut sangat memungkinkan karena melalui kurikulum 2013 pendidikan sejarah akan diakomodir sehingga target yang akan dicapai mengenai sasaran sesuai dengan penjelasan yang telah dipaparkan. Peserta didik akan mampu menganalisa dan memetik pelajaran dari peristiwa sejarah yang telah dipelajarinya di sekolah.

Kurikulum 2013 pendidikan sejarah lebih mempertegas tujuan dari pembelajaran sejarah di sekolah yang mendorong peserta didik agar berfikir kreatif dan kritis. Hasan (2012: iv) mengemukakan bahwa "Dalam wilayah pendidikan, sejarah harus menjadi sesuatu yang memberikan pelajaran bagi kehidupan manusia. Peristiwa-peristiwa sejarah di in dengan pendekatan normatif, dengan melihat baik dan buruk."

Oleh karena itu, kurikulum 2013 akan membentuk peserta didik yang memiliki kualitas yang baik, sehingga mampu mengambil nilai baik dan buruknya dari peristiwa sejarah di masa lampau kemudian diolah dalam otak mereka untuk direkonstruksi kembali menjadi sebuah nilai yang positif, mengingat era global yang sedang mereka hadapi. Pendidikan sejarah harus dapat mempersiapkan peserta didik dengan kualitas yang baik. Adapun kualitas yang harus dimiliki peserta didik menurut Marli (XX:4) yakni: “(1) Kualitas yang mampu melakukan kritik terhadap setiap informasi yang harus diterimanya. (2) Mampu mengenal berbagai bias yang terkandung di dalam informasi tersebut. (3) Mampu menarik berbagai simpulan dari informasi tersaring dan teruji kebenarannya. (4) materi pendidikan sejarah harus memiliki kualitas dan karakteristik yang mampu mengembangkan kualitas yang dimaksudkan".

Merujuk dari tujuan pendidikan sejarah dan kualitas yang harus dimiliki oleh peserta didik, kurikulum 2013 pendidikan sejarah sudah tepat dengan konteks masa kini. Karena peserta didik akan mampu bersaing di era global tanpa melupakan jati diri bangsa karena mereka telah dibekali kesadaran sejarah dalam pembelajaran di sekolahnya. Sebagai upaya mengenalkan diri peserta didik dengan lingkungannya, pengembagan peristiwa-peristiwa lokal dalam pembelajaran sejarah sangatlah urgen dan bagian yang tak terpisahkan dari 
peristiwa sejarah nasional. Dalam kaitan dengan hal ini, Hasan dalam Mulyana (2007:178-179) mengungkan bahwa:

"Dalam posisi arah dan tujuan pendidikan sejarah haruslah mempersiapkan peserta didik untuk hidup di masyarakat. Dalam posisi ini keberadaan sejarah lokal akan memegang posisi utama karena ia berkenaan dengan lingkungan terdekat dengan budaya peserta didik. Sebuah catatan penting dalam konteks tersebut ialah materi sejarah lokal harus pula disajikan tidak dalam perspektif ilmu sejarah tetapi dalam perspektif pendidikan. Oleh karena itu, keterkaitan dan penafsiran materi sejarah lokal jangan sampai menimbulkan konflik dengan kepentingan sejarah nasional dan upaya membangun rasa persatuan, perasaan kebangsaan, dan kerjasama antardaerah dalam membangun kehidupan kebangsaan yang sehat, cinta damai, toleransi, penuh dinamika, kemampuan berkompetisi dan berkomunikasi”.

Belajar sejarah berarti peserta didik mampu berpikir kritis dan mampu mengkaji setiap perubahan di lingkungannya, serta memilikikesadaran akan perubahan dan nilai-nilai yang terkandung dalam setiapperistiwa sejarah. Pembelajaran sejarah yang baik adalah pembelajaran yang mampu menumbuhkan kemampuan siswa melakukan konstruksi kondisi masa sekarang dengan mengkaitkan atau melihat masa masa lalu yang menjadi basis topik pembelajaran sejarah. Kemampuan melakukan konstruksiini harus dikemukakan secara kuat agar pembelajaran tidak terjerumus dalam pembelajaran yang bersifat konservatif. Kontekstualitassejarah harus kuat mengemuka dan berbasis pada pengalaman pribadi para siswa. Apalagi sejarah tidak akan terlepas dari konsep waktu, kontinuitas dan perubahan. (Surbakti, 2010: 4)

Pada gilirannya, hal menentukan bahwa pembelajaran sejarah lokal atau kejadian lokal di atas, sangat bergantung pada kemampuan kompetensi guru sejarah itu sendiri. Kreatifitas guru sejarah, dalam hal ini, jelas sangat dituntut untuk mengembangkan peristiwa-peristiwa lokal dalam pembelajaran sejaran di sekolah. Akhirnya, pengakuan jati diri daerah sebagai bagian integarasi bangsa Indonesia, sedikit banyak akan tercapai dan dapat memperkuat keutuhan NKRI.

\section{SIMPULAN}

Peristiwa-peristiwa lokal di atas, merupakan sebagian kecil dari peristiwa lokal yang pernah terjadi di Tasikmalaya. Dalam konteks kontemporer, banyak sekali kejadiankejadian lokal di Tasikmalaya yang masih perlu digali dan dikembangkan. Diperlukan penelitian dan pengkajian lebih mendalam tentang sejarah lokal, karena masih sedikit sekali sumber sejarah lokal untuk dijadikan bahan ajar dalam pembelajaran sejarah di sekolah. Bahkan, objek kajian penelitian dapat dikembangkan tidak hanya pada sejarah politiknya, akan tetapi setiap perubahan social, budaya, ekonomi yang terjadi di sekitar lingkungan tempat tinggal siswa dapat dijadikan sebagai kajian sejarah.

Selain itu, dalam pembelajaran sejarah berbasis sejarah lokal akan tercapai kearifan lokal dalam diri peserta didik melalui tokoh atau peristiwa yang bersifat lokal sehingga peserta didik peka terhadap lingkungan sekitar, menghargai keragaman budaya serta mengenal jatidirinya. Peristiwaperistiwa lokal di Tasikmalaya, juga di daerah akan mampu menegaskankan identitas/jati diri sebagai bagian dari bangsa Indonesia yang luas dan utuh.

\section{REFERENSI}

Hasan, S. Hamid. 2012. Pendidikan Sejarah Indonesia. Bandung: Rizqi Press

Hasan, S. Hamid, Pengembangan Kompetensi Berfikir Kritis dalam Pembelajaran Sejarah, Makalah: Seminar IKAHIMSI di UPI, 8 April 2008

Hasan, S. Hamid, Kurikulum Sejarah dan Pendidikan Sejarah Lokal, dalam Agus Mulyana \& Restu Gunawan. (2007). Sejarah Lokal Penulisan dan Pembelajaran di Sekolah, Bandung: Salamina Press

Mulyana, Agus \& Restu Gunawan. 2007. Sejarah Lokal Penulisan dan Pembelajaran di Sekolah. Bandung: Salamina Press

Naim, Ngainun \& Achmad Sauqi. 2012. Pendidikan Multikultural Konsep dan Aplikasi. Yogyakarta: Ar-Ruzz Media

Sjamsuddin, Helius \& Ismaun. 1996. Pengantar Ilmu Sejarah. Jakarta: Departemen Pendidikan dan Kebudayaan Direktorat Jenderal Pendidikan Tinggi

Supardan, Dadang 2004. Kesadaran Sejarah Berbasis Pendekatan Multikultural dan Perspektif Sejarah Lokal, Nasional, Global dalam Integrasi Bangsa. Disertasi SPS UPI Bandung: Tidak diterbitkan

Supardi \& Saliman. (XX). Penanaman Nilai dalam Pembelajaran IPS di SMP. Pdf Sumber tersedia di: http://staff.uny.ac.idsystemfilespenelitianSaliman, \%20 Drs.\%20M.Pd.Pendidikan\%20nilai\%20dalam\%20 pembelajaran\%20IPS.pdf (Diakses 23 September 2013)

Supriatna, Nana. Konstruksi Pembelajaran Sejarah Lokal untuk Memahami Isu-Isu Sosial, HISTORIA Jurnal Pendidikan Sejarah: No.11. Vol VI (Juni 2005)

Surbakti, Y.R. 2010. Paradigma Pembelajaran Sejarah Berbasis Konstruktivisme. Yogyakarta: Jurnal SPPS Vol. 24 No.1 Sumber tersedia: http://www. usd.ac.idlembagalppmf113Jurnal $\% 20$ Historia $\% 20$ Vitaevol24no1 april2010PARADIGMA\% 20 PEMBELAJARAN\%20SEJARAH\%20YR\%20Subakti.pdf (Diakses 21 September 2013)

Winarti, Murdiyah. XX. Sejarah Lokal: (Pengertian, Konten dan Pengajaran). Sumber tersedia di: http:// file.upi.eduDirektoriFPIPSJUR. PEND. SEJARAH1 96005291987032-MURDIYAH WINARTIPeng sej Lokal.pdf (Diakses 26 September 2013)

Wiriatmadja, Rochiati. 2002. Pendidikan Sejarah Indonesia, Perspektif Lokal Nasional dan Global. Bandung: Historia Utama Press

Wineberg, Sam. 2006) Berfikir historis, memetakan masa depan mengajarkan masa lalu. Jakarta: Yayasan Obor Indonesia 
Yanyan Hardiana

Pembelajaran Sejarah Indonesia Berbasis Peristiwa-Peristiwa Lokal di Tasikmalaya untuk. Meningkatkan Kemampuan Berpikir Kritis

Winecoff, Herbert L. 1987. Values education: concepts and models. (Indonesia \& State University of New York Technical Assistance Program, A World Bank Sponsored Program). Bandung: Fakultas Pasca Sarjana IKIP Bandung.
Wiriaatmadja, R. 2002. Pendidikan sejarah di Indonesia, perspektif lokal, nasional dan global. Bandung: Historia Utama Press. 